University of Nebraska - Lincoln

DigitalCommons@University of Nebraska - Lincoln

Educational Psychology Papers and

Publications

Educational Psychology, Department of

November 1989

\title{
Assessing and Treating Social Skills Deficits: A Case Study for the Scientist-Practitioner
}

Stephen N. Elliot

University of Wisconsin-Madison

Susan M. Sheridan

University of Nebraska-Lincoln, ssheridan2@unl.edu

Frank M. Gresham

Louisiana State University

Follow this and additional works at: https://digitalcommons.unl.edu/edpsychpapers

Part of the Educational Psychology Commons

Elliot, Stephen N.; Sheridan, Susan M.; and Gresham, Frank M., "Assessing and Treating Social Skills Deficits: A Case Study for the Scientist-Practitioner" (1989). Educational Psychology Papers and Publications. 36.

https://digitalcommons.unl.edu/edpsychpapers/36

This Article is brought to you for free and open access by the Educational Psychology, Department of at DigitalCommons@University of Nebraska - Lincoln. It has been accepted for inclusion in Educational Psychology Papers and Publications by an authorized administrator of DigitalCommons@University of Nebraska - Lincoln. 


\title{
SCIENTIFIC PRACTITIONER
}

\section{Assessing and Treating Social Skills Deficits: A Case Study for the Scientist-Practitioner Stephen N. Elliott and Susan M. Sheridan University of Wisconsin-Madison}

\author{
Frank M. Gresham
}

Louisiana State University

\begin{abstract}
The goals of this article were to examine various empirically proven assessment and intervention methods that can be used to remediate social skills problems and to illustrate the utilization of these methods in a case study. The case study concerned a withdrawn elementary child, her teacher, and her parents in a joint consultative intervention designed to increase her interactions with peers illustrated in the course of assessment and treatment. Combining the manipulation of antecedent/consequent events with modeling or coaching procedures constituted an effective multimethod approach to providing psychological services.
\end{abstract}

The identification and treatment of socially deficient schoolchildren warrants the attention of psychological researchers and practitioners alike. Recent research has indicated that social skills deficits in early childhood, if untreated, are relatively stable over time, are related to poor academic performance, and may be predictive of social adjustment problems and serious psychopathology in adolescence and adulthood (Coie \& Dodge, 1983; Coie \& Krehbiel, 1984; Cowen, Pederson, Babigian, Izzo, \& Trost, 1973; Parker \& Asher, 1987; Roff, Sells, \& Golden, 1972). In brief, children who persistently exhibit social skills deficits experience both short- and long-term negative consequences, and these negative consequences seem to be precursors of more severe problems later in life. Because of the paucity of formal measures of children's prosocial behaviors, psychologists and educators face some significant assessment and treatment challenges. The purpose of this article is to illustrate state-of-the-art social skills assessment and treatment concepts and technology through a case study of a withdrawn elementary student. Before presenting the case, we review some fundamental assumptions and definitional issues and provide a brief examination of the social skills assessment and treatment literature that has influenced our functioning on the case. 


\section{DEFINITIONS, ASSUMPTIONS, AND CLASSIFICATION}

Several definitions of children's social skills have been advanced in recent years. These include the peer acceptance definition, the behavioral definition, and the social validity definition. In the peer acceptance definition, children are characterized as socially skilled if they are accepted by peers. Various sociometric indices of peer acceptance status have been used to operationalize this definition (see McConnell \& Odom, 1986, for a review). A major disadvantage of the peer acceptance definition is that the specific behaviors that lead to a child's acceptance or rejection by peers cannot be identified. Thus, although this definition can provide a useful criterion for screening and for outcome assessment, it is of little use in designing remedial strategies.

In the behavioral definition of social skills, socially skilled behaviors are characterized as behaviors exhibited in specific situations in which there is maximum probability of reinforcement contingent on one's social behavior. An advantage of this definition is the identification of specific social behaviors, their controlling variables, and the situations in which these behaviors are performed. Thus, the behavioral definition of social skills has direct relevance for intervention of strategies designed to remediate social skills deficits. The behavioral approach, however, does not ensure that these social behaviors are socially important or socially significant. Merely increasing the frequency of certain behaviors that researchers define a priori as social skills may not affect goals or outcomes valued by society at large.

The social validity definition of social skills is the most heuristic definition. According to this definition, social skills are behaviors exhibited in specific situations that help in assuring a child's attainment of important social outcomes (Gresham \& Elliott, 1987). Important social outcomes for children include (a) acceptance by the peer group, (b) positive judgments of social skills by significant others (e.g., parents and teachers), (c) academic competence, (d) adequate self-concept or self-esteem, and (e) adequate psychological adjustment (i.e., absence of psychopathology). This definition essentially is a combination of the peer acceptance and behavioral definitions. Specific behaviors are identified and related to important criteria for indexing adequate social functioning.

Fundamental to any conceptualization of social skills are seven assumptions identified by Michelson, Sugai, Wood, and Kazdin (1983, p. 3):

1. Social skills are primarily acquired through learning (e.g., observation, modeling, rehearsal, and feedback).

2. Social skills comprise specific and discrete verbal and nonverbal behaviors.

3. Social skills entail both effective and appropriate initiations and responses.

4. Social skills maximize social reinforcement. 
5. Social skills are interactive by nature and entail effective and appropriate responsiveness.

6. Social skill performance is influenced by the characteristics of an environment.

7. Deficits and excesses in social performance can be specified and targeted for intervention.

These pragmatic assumptions, along with a social validity definition, have provided direction to our assessment practices and treatment planning. In sum, social skills is defined as learned behaviors that affect interpersonal relations with peers and adults. We do not consider social skills as global personality traits; rather, they are discrete, situation-specific behaviors that are affected by age, sex, social status, and the persons with whom one interacts.

Social skills deficiencies can be categorized by four basic types, depending upon a child's knowledge of how to perform the behavior in question and the presence or absence of interfering cognitive, emotional, or behavioral responses (Gresham, 1981). This conceptualization of social skills deficits was influenced by Bandura's (1977) distinction between acquisition and performance deficits and includes skills deficit, performance deficits, self-control skills deficits, and self-control performance deficits. It should be noted that this four-cell classification schema is based on clinical observation and awaits empirical validation.

The concept of interfering responses is crucial to understanding self-control and performance deficits, because it is assumed that these responses interfere with the acquisition and/or performance of social skills. The term self-control refers to the probability that an interfering response (e.g., aggression toward a peer, noncompliance with a request, anxious avoidance of eye contact, taking materials away from a peer) will override the performance of a socially skilled response. Thus, an interfering response can be viewed from a behavior covariation perspective when target behaviors are selected (Kazdin, 1985), and it functions as a controlling response because it can prevent the acquisition or performance of a social skill response.

Interfering responses are best conceptualized via a three-part response mode system, such as that outlined by Nelson and Hayes (1979), to guide behavioral assessments. The three response modes for any behavior are cognitive-verbal, physiological-emotional, and overt-motoric. Behaviors expressed through one or more of these response modes can interfere with acquisition and with performance of a prosocial behavior. For example, anxiety (an emotional response) can either prevent the learning of appropriate social initiations to peers or the performance of such a social skill. Similarly, physical aggressive behavior (an overt-motoric response) can prevent the acquisition or enactment of social skills. Clearly, the identification and treatment of interfering behaviors is critical to the successful performance of prosocial behaviors. Thus, one's assessment and treatment of social skills must take into consideration the possibility of a wide range of both negative and positive target behaviors. 


\section{ASSESSMENT OF SOCIAL SKILLS}

Methods for assessing social skills vary along three primary dimensions: source, specificity, and proximity of report to time of behavior performance (Gresham \& Reschly, 1988). Thus, methods can rely on different sources, such as parents, teachers, peers, trained observers, or the subjects themselves. From these sources, information is provided that varies in specificity, ranging from global or molar descriptions to molecular behaviors. Finally, to illustrate variation of assessment methods with respect to proximity of report or observation to time of behavior performance, we can contrast, for example, direct observations, which occur concurrently with the target behavior, with the completion of a behavior rating scale or analogue role-play, which can be quite removed in time and space from the actual occurrence of a target behavior. The combination of these dimensions plus the content focus of the method influences the utility or purpose of an assessment.

In general, the purposes of social skills assessments concern either identification/classification or intervention/program planning. The critical characteristic that differentiates assessment methods is the extent to which a method allows for a functional analysis of behavior (i.e., the extent to which an assessment procedure provides data on the antecedent, sequential, and consequent conditions surrounding a molecular behavior). Table 1 characterizes social skills assessment methods along the dimensions of source, specificity, and temporal proximity of report. A detailed examination of the psychometric properties and limitations of each of these methods is provided elsewhere (Elliott, 1988).

\section{Process of Assessment}

As with the psychological assessment of any problem, the process of social skills assessment can be characterized by a series of hypothesis-testing sequences. Hypotheses are generated in an attempt to answer questions regarding identification, intervention, and evaluation of treatment effects. Hypotheses may be generated based on information that is available at any given point in the assessment process and then tested at subsequent points through the gathering of additional information. Comprehensive assessments allow one to draw conclusions regarding problem severity, interfering behaviors, necessary intervention strategies, and the degree of treatment success.

A standard battery of tests or methods for assessing social skills does not exist. Rather, the hypotheses generated dictate the direction of assessment, the questions to be answered, and the methods to be used. Assessment should proceed from global to specific to allow appropriate planning of interventions. In contrast, evaluation of intervention success typically proceeds in the opposite direction, moving from behavior-specific outcomes to more global analyses on important social outcomes.

Ideally, practitioners should use assessment methods possessing the attributes 
Table 1

Overview of Social Skills Assessment Methods and Their Characteristics

\begin{tabular}{|c|c|c|c|}
\hline Method & $\begin{array}{c}\text { Source of } \\
\text { information }\end{array}$ & $\begin{array}{l}\text { Specificity of } \\
\text { information }\end{array}$ & $\begin{array}{l}\text { Proximity to } \\
\text { target behavior }\end{array}$ \\
\hline Sociometrics & Peers & Molar (social status) & Removed in time \\
\hline Direct observations & $\begin{array}{l}\text { Third party } \\
\text { (psychologist/ } \\
\text { teacher) }\end{array}$ & $\begin{array}{l}\text { Molecular (discrete } \\
\text { social behaviors }\end{array}$ & Close in time \\
\hline Ratings & $\begin{array}{l}\text { Teacher } \\
\text { Parent } \\
\text { Self }\end{array}$ & $\begin{array}{l}\text { Molar-molecular } \\
\text { (domain-specific } \\
\text { behavior) }\end{array}$ & Removed in time \\
\hline Role-plays & $\begin{array}{l}\text { Third party } \\
\text { (psychologist/ } \\
\text { teacher) }\end{array}$ & Molecular & $\begin{array}{r}\text { Removed in time } \\
\text { and situation }\end{array}$ \\
\hline Behavioral interviews & $\begin{array}{l}\text { Child } \\
\text { Teacher } \\
\text { Parent }\end{array}$ & Molecular & Removed in time \\
\hline
\end{tabular}

of reliability (i.e., consistency of measurement), validity (i.e., capability of answering a given assessment question), and practicality (i.e., reasonable costs of collecting information) (Gresham \& Cavell, 1986). Unfortunately, few social skills assessment methods meet all of these criteria. Easily administered instruments that are useful for screening purposes (e.g., self-report scales) are of little help in designing interventions. Other methods requiring considerably more effort from assessors and clients (e. g., naturalistic observations and self-monitoring) often have equivocal or unknown psychometric properties (Dodge, Murphy, \& Buchsbaum, 1984; Gresham \& Elliott, 1984). Moreover, there is a tendency for assessment data obtained from different sources to correlate moderately at best, and more often to correlate quite low (Achenbach, McConaughy, \& Howell, 1987). As a safeguard, multiple sources of information are required when assessing social skills.

To increase the likelihood of accurate identification/classification decisions, we recommend the use of direct observation of the target child and nontarget peers in multiple settings; behavioral interviews with both the referral source and the target child; rating scale data, preferably norm-referenced, on both a social skills scale and a problem behavior scale completed by the referral source and possibly the target child; and sociometric data from the target child's classmates. Regarding intervention decisions, data contributing to a functional analysis of important social behaviors is imperative. This type of data usually results from many direct observations across settings; behavioral role-plays with the target child; and teacher and parent ratings of socially valid molecular behaviors. If persons other than a psychologist will be involved in providing the treatment, behavioral interviews with the treatment agent(s) also will be important to assess the treatment setting, the acceptability of the final treatment plan, and the integ- 
rity with which the plan is implemented. Tables 2 and 3 provide a summary of a heuristic assessment sequence and important questions resulting from the assessment of social skills.

\section{TREATMENTS FOR SOCIAL SKILLS DEFICITS}

A number of procedures have been identified as effective treatment methods for social skills deficits. The myriad of procedures, however, can be classified under four major headings: (a) operant conditioning, (b) modeling, (c) coaching, and (d) social-cognitive procedures. Operant conditioning interventions consist primarily of providing social or material reinforcement of targeted prosocial behaviors in naturalistic or analog settings. Modeling interventions involve the training of desired social behaviors through filmed, videotaped, or live demonstrations of the skills to be acquired. Coaching procedures consist of direct verbal instruction, accompanied by discussion of the desired social behaviors. Finally, social-cognitive interventions focus on any of several cognitive processes that have been associated with social competence and problem solving. In practice, behavioral rehearsal is often incorporated into treatment, and most effective social skills interventions are combined procedures rather than a single technique. Interventions

Table 2

Summary of Actions and Purposes for a Systematic Assessment Sequence of Social Skills

1. Teacher ratings of social skills
A. Estimation of frequency of behaviors
B. Estimation of behavior's importance to teacher
C. Tentative estimation of skill and performance deficits
D. Guideline for teacher interview and direct observations

2. Parent ratings of social skills

A. Estimation of cross-setting generality of deficits

B. Parent's perceived importance of social behaviors

C. Guideline for parent interview

3. Teacher interview

A. Further delineation of target behaviors

B. Functional analysis of behavior in specific situations

C. Selection of target behaviors based upon importance ratings and teacher's rankings

4. Parent interview
A. Further delineation of target behaviors
B. Functional analysis of behavior in specific situations
C. Selection of target behaviors based upon importance ratings and teacher's rankings

5. Direct observations of classroom behavior
A. Functional analysis of behavior
B. Direct measurement of behavior in applied setting
C. Observation of peer reactions to target child's behavior

6. Sociometrics using liked-most and liked-least nominations

A. Measurement of social preference and social impact

B. Classification of sociometric status (rejected, neglected, controversial)

7. Self-report of social skills - obtain child's perception of social behavior

8. Child interview 
Table 3

Important Questions to be Answered Based on Assessment Results

1. Which behaviors are skills deficits and which behaviors are performance deficits?

2. Are interfering behaviors present?

3. Does the behavior(s) occur across situations?

4. What is the functional analysis of the behaviors?
A. What events precede the occurrence of interfering behaviors?
B. What events follow the occurrence of interfering behaviors?
C. Does the classroom environment set the occasion for social skills to occur?
D. Do peer or teacher reinforce, ignore, or punish socially skilled behaviors?

5. Do classroom observations agree with teacher ratings and teacher interview?

6 . What is the child's sociometric status in the classroom?

Rejected: Interfering behaviors likely to be aggressive, disruptive behaviors

Neglected: Interfering behaviors likely to be social withdrawal, anxiety, etc.

Controversial: Child likely to have combination of socially skilled behaviors and externalizing behaviors (disruption, aggressive behavior, etc.)

7. What behaviors are not occurring that teacher considers to be critical for classroom success?

8. What behaviors are not occurring that teacher does not consider critical or important for classroom success?

9. What is the child's perception of her or his own social behavior and sociometric status?

10. What interventions are likely to be successful with this child?

11. Can these interventions be implemented in the classroom?

12. If classroom-based interventions are not feasible, can these interventions be implemented through other means?

can be conceptualized as involving manipulation of antecedents and/or consequences, modeling, or cognitive-behavioral procedures. Table 4 provides examples of popular treatment strategies that illustrate each of these four categories.

\section{Effectiveness}

Schneider and Byrne $(1985,1988)$ reported the results of a major meta-analytic investigation that provided comparative effectiveness data for each of the four basic approaches to social skills intervention. From the extensive data provided by these researchers, it is clear that no single treatment approach or technique uniformly is effective. Rather, the effectiveness of social skills training procedures varies considerably among subjects (differing in age, sex, and handicapping condition), settings, and therapists.

Regarding withdrawn elementary students, which we discuss in the present case study, several general trends in treatment effectiveness can be extracted from the Schneider and Byrne $(1985,1988)$ meta-analytic investigations and a review of single-subject treatment studies by Mastropieri and Scruggs (19851986). First, from comparison of the mean effect sizes across all studies with all types of problems in the Schneider and Byrne data set, it was clear that operant techniques generally were more effective than modeling and coaching procedures, which in turn were more effective than social-cognitive methods. Second, treatments specifically for withdrawn students infrequently have involved coaching techniques, and the mean effect size data indicate that mod- 
eling is overwhelmingly more effective than operant and social-cognitive techniques. Third, Mastropieri and Scruggs's analyses of single-subject studies indicated that treatments involving direct reinforcement of interactive behaviors were most successful.

\section{Implementation Framework}

Regardless of the assessment and treatment focus, a general conceptual framework for social skills training can be described by the DATE strategy of Elliott, Gresham, and Heffer (1987). First, behaviors are defined and stated in observable terms. In addition, the antecedent and consequent conditions surrounding the behavior are defined. Second, behaviors are assessed by procedures described earlier in this article. Third, teaching strategies are prescribed to fit the student's needs as determined by the assessment. Fourth, the effects of the teaching procedures are evaluated empirically by the assessment methods upon which students were selected for training. This Define-Assess-TeachEvaluate (DATE) model, which is analogous to Bergan's (1977) well-known four-stage problem-solving schema, is applied continuously to each deficient social behavior that a student exhibits.

Although case-related hypotheses and idiosyncratic needs of a particular case will suggest appropriate assessment and intervention strategies, the DATE model provides a general framework for guiding the practitioner through the problemsolving process. As such, the model can be implemented through a series of five steps: (a) establishing the need for performing the behavior, (b) identifying the

Table 4

Popular Social Skills Training Strategies

Representative of Major Treatment Approaches

A. Manipulation of antecedents

1. Peer initiation strategies

2. Sociodramatics

3. Cooperative learning strategies

4. Ecological changes in environment

B. Manipulation of consequences

1. Reinforcement-based procedures

2. Group contingencies

3. Peer-mediated reinforcement

C. Modeling-based procedures

1. Symbolic modeling

2. Live modeling

3. Participant modeling

D. Cognitive-behavioral procedures

1. Goaching

2. Self-instruction, self-monitoring, self-reinforcement

3. Desensitization/flooding 
specific behavioral components of the skill (i.e., task analysis), (c) encouraging performance of the behavior through empirical procedures (i.e., modeling, coaching, operant, social-cognitive), (d) using behavior rehearsal and response feedback, and (e) applying generalization training. These five steps represent an easily implemented and effective approach to teaching social behavior.

\section{Generalization Training}

To be truly effective, behaviors taught in social skills training programs should generalize across time (i.e., maintenance), settings, individuals, and behaviors. Berler, Gross, and Drabman (1982) recommended that social skills interventions not be considered valid unless generalization to the natural environment can be demonstrated.

Application of social skills outside the training setting does not occur naturally; rather, generalization must be programmed actively into the training program (Weissberg, 1985). Stokes and Baer (1977) and Michelson et al. (1983) discussed several procedures, referred to as generalization facilitators, that enhance generalization beyond the specific aspects of an intervention. Examples of generalization facilitators are (a) teaching behaviors that are likely to be maintained by naturally occurring contingencies; (b) training across stimuli (e.g., persons, setting) common to the natural environment; (c) fading response contingencies to approximate naturally occurring consequences; (d) reinforcing application of skills across settings and to new and appropriate situations; and (e) including peers in training. By incorporating as many of these facilitators as possible into social skills interventions, and by offering "booster" sessions at regular intervals, maintenance and generalization of skills are enhanced.

We are now ready to examine a case illustrating state-of-the-art approaches to assessment and treatment. This case has been drawn from an actual assessment project, yet the treatment data are hypothetical.

\section{CASE STUDY}

\section{Background Characteristics}

Stacy is an 8-year-old, third-grade student with above average intellectual and language abilities. She is an only child, and lives in the country with her parents. Stacy's teacher requested services from the school psychologist-consultant because of her apparent lack of friends. Specifically, Stacy was described as very withdrawn during most of the school day, both in the classroom and on the playground. She rarely participated in social activities with classmates and preferred to wander or sit by herself, rather than with peers. Previous teachers had expressed similar concerns, but were unsuccessful in remediating Stacy's social deficiencies. 
Stacy's family participated in few social activities. In a parent-teacher conference, Stacy's parents reported that she had little opportunity to interact with peers at home. She rarely invited a friend over to play or visited the home of a classmate or neighbor.

The Barclay Classroom Assessment System (Barclay, 1978) was administered annually at Stacy's school as part of a screening program for at-risk children. The screening included a 28 -item sociometric nomination scale, with both positive and negative items. ${ }^{1}$ For two consecutive years, Stacy was nominated least frequently for any items, positive or negative, of all her classmates. This suggested that Stacy may have been ignored or neglected consistently by her peers.

Because of the chronicity and severity of Stacy's difficulties across settings, a conjoint behavioral consultation approach was adopted by the school psychologist (Sheridan, 1988). In this method of service delivery, the school psychologist worked with Stacy's parents and teacher to encourage them to address her social difficulties in a joint, cooperative problem-solving effort. The formal behavioral consultation stages of problem identification, problem analysis, treatment implementation, and treatment evaluation provided the framework for specifying Stacy's social problems, developing an intervention program to remediate her difficulties across settings, and evaluating the effectiveness of the behavioral program systematically.

\section{Problem Identification Stage}

In the problem identification stage of consultation, the school psychologist worked with Stacy's parents and teacher to identify specific problem(s) to be targeted for intervention. A multisource, multimethod assessment procedure was instituted. Specific assessment procedures included a conjoint behavioral interview with Stacy's parents and teacher (Kratochwill \& Bergan, in press); general and specific behavior ratings by others - namely, the parent and teacher forms of the Child Behavior Checklist (Achenbach \& Edelbrock, 1983, 1986) and the parent and teacher forms of the Social Skills Rating System (Gresham \& Elliott, in press); a self-report measure, the Self-Perception Profile for Children (Harter, 1985); and direct observations of Stacy's interactive behaviors.

Problem Identification Interview (PII). Stacy's parents and teacher met with the school psychologist for a formal Problem Identification Interview (PII) to discuss concerns regarding Stacy's social behaviors at home and at school. The goals of the PII were to define the problem in behavioral terms; to tentatively identify Stacy's withdrawn behaviors in terms of antecedent, consequent, and

\footnotetext{
1 Several sociometric classification systems are available to identify children who may be socially "at risk" (Coie, Dodge, \& Coppotelli, 1982; Peery, 1979; Vosk, Forehand, Parker, \& Rickard, 1982). McConnell \& Odom (1986), and Bullock, Ironsmith, and Poteat (1988) provide comprehensive reviews of various sociometric assessment methodologies and interpretation schemes.
} 
sequential conditions; to tentatively identify her social behavior strengths; and to establish a procedure for collection of baseline data. In conjoint behavioral consultation, the emphasis is placed on eliciting information from both parents and teachers for a comprehensive and global specification of a child's difficulties across settings.

During the PII, Stacy's parents described her primary social problem as having few friends. They indicated that peers rarely called Stacy to ask her to play and that she very infrequently sought out friends (e.g., invited them over to play). When prompted, Stacy often became anxious or rebellious, and her parents reported that they have therefore allowed her to remain isolated from neighborhood and school peers.

Stacy's teacher described similar behaviors at school. According to her teacher, Stacy rarely initiated social interactions in the classroom or during recess and generally lacked a desire to establish friendships. When approached by peers, she often did not respond or she outwardly refused their bid for interaction. When Stacy did participate in a social activity, it generally lasted for a very brief period (i.e., less than a minute).

Stacy's parents and teacher especially were concerned with the persistence of her behaviors. Her difficulties had been apparent for at least 2 years, and other children had stopped approaching her because of her lack of responsiveness. More and more, she preferred to wander or sit alone, rather than with peers.

To obtain a baseline estimate of Stacy's social behaviors, her parents and teacher were asked to record (a) instances in which Stacy initiated interactions with peers; (b) instances in which peers initiated interactions with Stacy; (c) Stacy's response to initiations made by others; and (d) the approximate length of time an interaction lasted. During 2 weeks of baseline data collection at home, Stacy did not interact with peers at all. Thus, no initiating or responding behaviors were observed. At school, Stacy was approached by peers an average of three times daily. She was observed to respond positively to $21 \%$ of initiations made by peers (Figure 1). However, she was observed to fail to respond, or to decline interactions (e.g., "No, I don't want to play"), an average of twice per day. She was never observed to approach other children, and the duration of the peer-initiated interactions were brief (usually less than a minute in length).

To keep the data collection manageable, and to enhance the evaluation methodology, responding to peer initiations was prioritized as the target behavior of initial concern. Upon an increase in the percentage of positive responses to peers, initiation of peer interactions would become the focus. Repeated measurement of both components of social interaction, however, was desired.

Stacy's parents and teacher indicated that they would like to see Stacy initiate and respond to peers at a level more similar to that of her peers. With the consultant, they established a goal of positive response to at least $85 \%$ of initiations made by peers at home and at school. To follow attainment of this target, they es- 


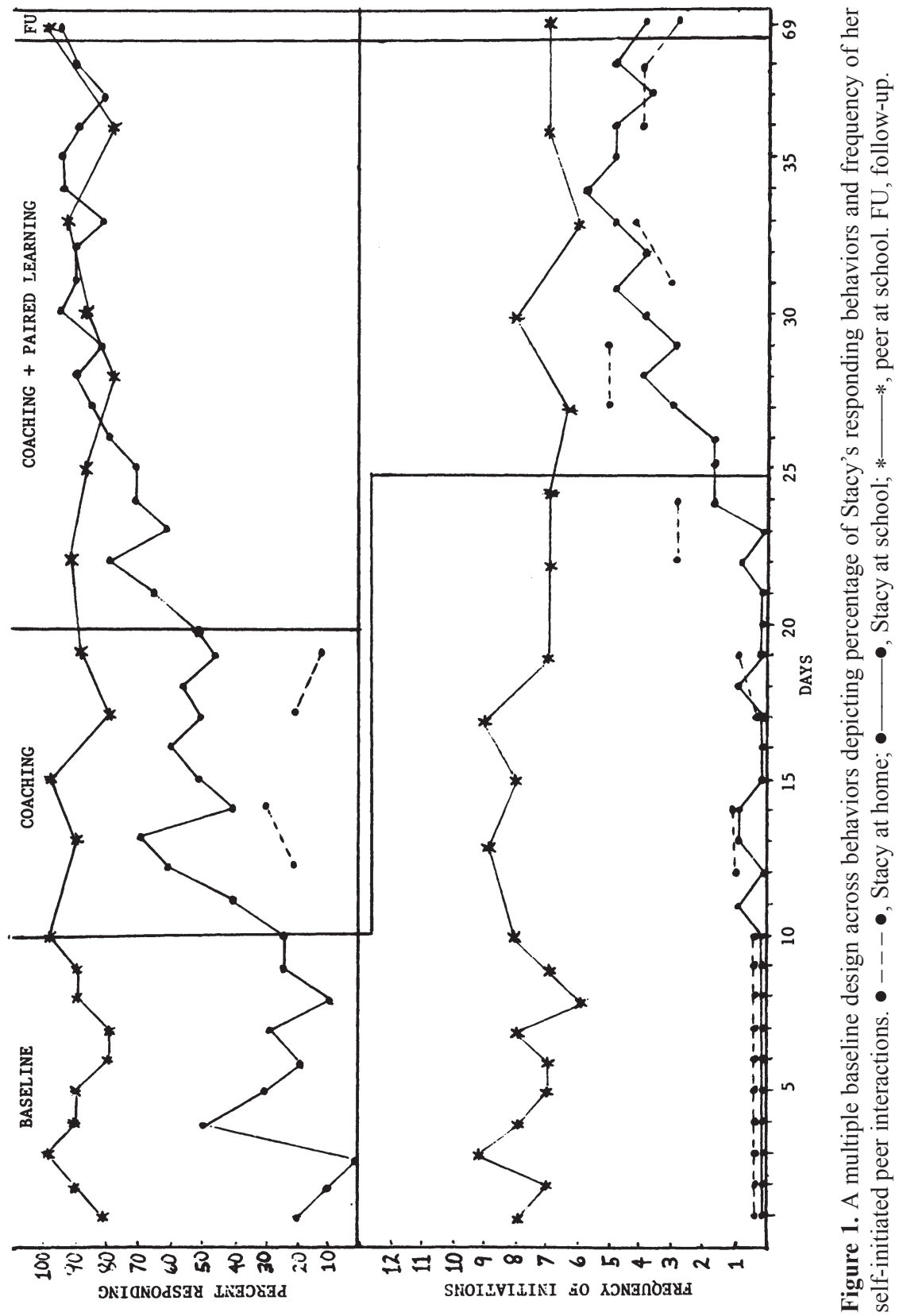


tablished a subsequent goal of initiating at least three activities with peers each day at school, and once per day at home.

Behavior Rating Scales. The Child Behavior Checklist (CBCL) (Achenbach \& Edelbrock, 1983), and Child Behavior Checklist-Teacher Report Form (TRF) (Achenbach \& Edelbrock, 1986) were completed to obtain global parent and teacher ratings of Stacy's overall behavior adjustment, and to identify behavioral clusters that may interfere with Stacy's prosocial behaviors.

Stacy's total T scores on the CBCL and TRF were 62 and 60, respectively. These placed her behaviors at the 84th and 87th percentiles, and within the normal range for girls her age. The specific response patterns, however, suggested problems in the area of social withdrawal. Her T scores of 85 and 88 on the CBCL and TRF Social Withdrawal subscales were extremely high, and were the only narrow-band subscales exceeding the 98th percentile on either scale. Her parents' responses also resulted in a slightly elevated score on the Depressed subscale ( $\mathrm{T}=65 ; 93 \mathrm{rd}$ percentile), but still within the normal range. Responses that were consistent across both the CBCL and TRF indicated that Stacy very often was shy and withdrawn, very often felt lonely, and very often liked to be alone.

Along with global ratings of Stacy's behaviors, the Social Skills Rating System-Parent (SSRS-P) and -Teacher (SSRS-T) forms ${ }^{2}$ (Gresham \& Elliott, in press) were completed. The Social Skills Rating System includes behavioral checklists designed to measure the frequency and importance of specific social behaviors. Specific prosocial behaviors are rated on a Frequency scale from 0 (never true) to 2 (very often true), and on an Importance scale from 0 (not important) to 2 (critical). Scores on the 50-item SSRS-T range from 0 (low) to 100 (high), and scores on the 60-item SSRS-P range from 0 (low) to 120 (high). The Importance ratings on the SSRS are used to facilitate target behavior selection; the higher the importance rating, the more critical it is for functioning in a particular setting. The likelihood of identifying socially significant skills deficits is increased by identifying items that parents and/or teachers rate as 0 or 1 on behavior Frequency, and 2 on Importance.

Information about Stacy obtained from both the SSRS-T and SSRS-P suggested low levels of social interaction. On the SSRS-T, Stacy received a total score of 34, placing her at the 14th percentile nationally with regard to general social skills. Responses on individual items resulted in raw scores equivalent to the 22nd percentile on Self-control, the 6th percentile on Assertion, and the 11 th percentile on Compliance. Individual factor scores were computed, yielding mean item ratings of 1.13, .43, and .85 for the Self-control, Assertion, and Compliance factors, respectively. Coupled with moderate to high ratings on all items

\footnotetext{
${ }^{2}$ The item contents of the final published versions of the SSRS-T and SSRS-P vary slightly from the versions used in this study. A Social Skills Rating System-Student (Gresham \& Elliott, in press) version also is available from American Guidance Service for elementary (Grades 3-6) and junior/senior high-school students (Grades 6-12).
} 
on the Internalizing Behavior factor, these teacher ratings suggested, on the basis of either locally or nationally established criteria, that Stacy was indeed a withdrawn child. Mean item ratings lower than 1 on a factor indicate serious performance deficits and/or possibly skills deficits. Specific items on the Assertion factor that were matters of concern (i.e., Frequency rating $=0$ and Importance rating $=2$ ) included "Invites others to play," "Initiates conversations with peers," "Joins ongoing activity or group without being told," and "Gives compliments to peers."

On the SSRS-P, Stacy received a total score of 61, which is in the low normal range and at the 25th percentile compared to other children her age. Her parent's responses resulted in ratings equivalent to the 53rd percentile for Self- control, the 2nd percentile for Assertion, the 41st percentile for Compliance, and the 22nd percentile for Responsibility. Individual item scores for each factor yielded mean ratings of 1.25 (Self-control), .67 (Assertion), 1.3 (Compliance), and 1.53 (Responsibility). Specific items that were rated by both Stacy's parents and teacher as never true included "Invites others to play," "Initiates conversations with others rather than waiting for others to talk first," "Joins an ongoing activity or group without being told to do so," and "Gives compliments to peers." These items were all characterized as "Important" or "Critical" by both Stacy's parents and teacher, but were either not in her response repertoire or occurred very infrequently.

Self-report. The Self-Perception Profile for Children (SPPC) (Harter, 1985) was completed to obtain an estimate of Stacy's self-perceptions on several scales: Scholastic, Social Acceptance, Athletic Competence, Physical Appearance, Behavioral Conduct, and Global Self-Worth. Items on these scales are rated either $4,3,2$, or 1 , where 4 represents the most adequate self-judgment and 1 represents the least adequate self-judgment. Mean scores below 3.0 on any scale are considered subaverage and mean ratings below 2.0 are considered to be indicative of poor self-efficacy and low self-worth. Stacy's individual profile suggested very low self-perceptions regarding her social acceptance (i.e., ability to make friends, doing things with friends, liking to have more friends), and moderately low feelings of global self-worth (i.e., often unhappy with self, and unhappy with the way one is). Her mean subscale scores ranged from a low of 1.3 on Social Acceptance to a high of 3.3 on Behavioral Conduct.

Direct Observations. To assess the reliability of parent and teacher ratings, the psychologist conducted three baseline observation probes at school and two at home. A 30-minute event procedure was used to record occurrences of positive and negative initiating and responding behaviors. Conditional information (i.e., antecedent, consequent) was recorded to permit a functional analysis of social behavior patterns. Likewise, anecdotal information was reported to document ongoing behaviors descriptively and to obtain an estimate of the duration of the 
Student's Name:

observer:

Grade:

Date:

Time Observation Began:

Time Observation Ended:

Total observation Time:

Environmental/situational Information:

Behaviors to observe: Inltiating an interaction with a peer.

Responding to an initiation made by a peer.

Code: $I=$ In1tiating $\quad+=$ Positive Behavior

$R=$ Responding $\quad-$ = Negative Behavior

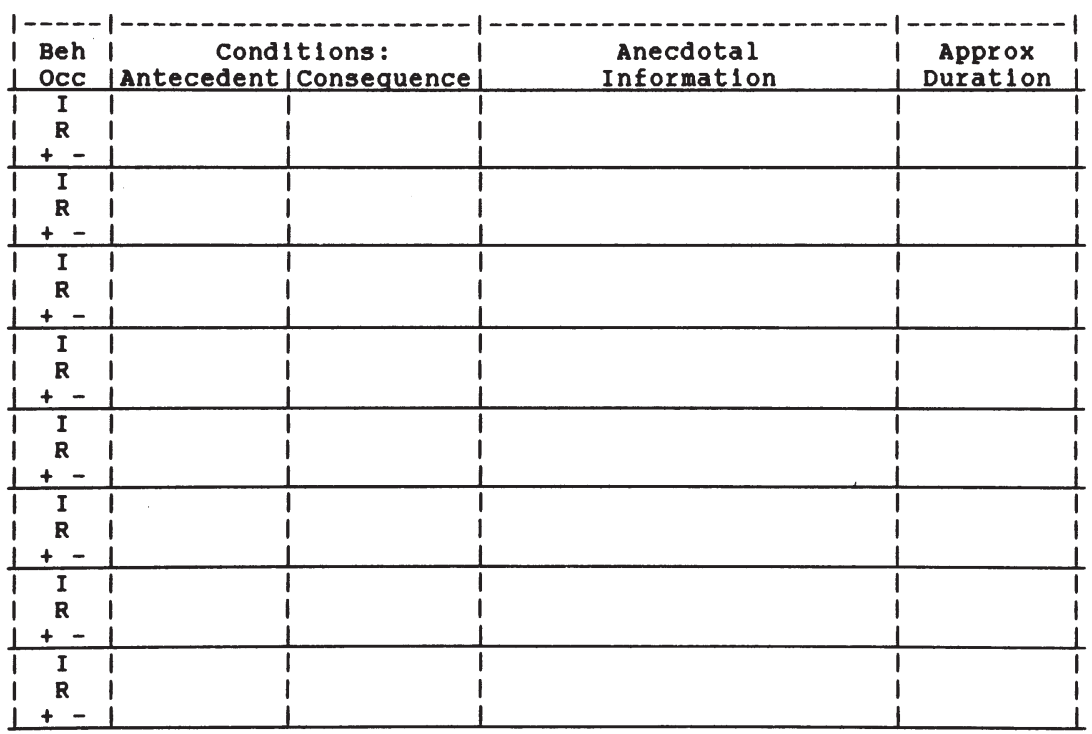

SUMMARY TOTALS

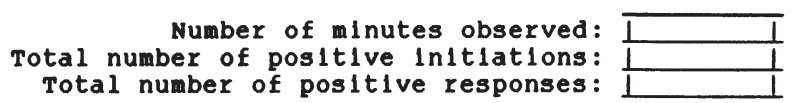

Figure 2. Direct observation form for coding the quality (positive or negative) and nature (initiating or responding) of Stacy's interactive behaviors.

interaction. Figure 2 provides an example of the direct observation form completed by the psychologist.

In the three, 30-min direct observations at school, Stacy was observed to respond positively to an average of $25 \%$ of initiations made by peers. Specifically, she was approached three times each day, and at least two of these approaches 
were rejected. Stacy was not observed to initiate an interaction with one or more peers during any of the observation probes. The observations of the psychologist and teacher were highly consistent, resulting in a reliability coefficient of .95 for the 90 min of observations.

As part of the observational procedures, anecdotal information was documented about the antecedent and consequent conditions surrounding Stacy's behaviors. A typical interaction pattern consisted of an approach behavior from a peer, followed by a brief response and termination of the interaction by Stacy. For example, following a social advance from a peer, Stacy either failed to respond, ignored bids for interaction, refused their requests, or responded in a constricted manner. Thus, peers' bids for interaction were not reinforced by Stacy, and they often subsequently neglected her when seeking meaningful interactions.

To obtain an estimate of typical interaction patterns within Stacy's peer group, direct observations were conducted weekly on a nonwithdrawn classmate, matched for sex and age. Identical observational procedures were utilized, yielding information on the frequency with which the classmate initiated and responded to interactions at school. On the average, the matched peer was observed to initiate slightly more than three interactions with peers, and respond positively to initiations made by others $89 \%$ of the time.

Because Stacy failed to interact with peers outside of school, the observations at home involved Stacy and her parents. Stacy spent the entire $30 \mathrm{~min}$ of the first observation alone. Specifically, she spent the first $10 \mathrm{~min}$ in her bedroom reading, 7 min looking out her bedroom window, and 13 min playing with dolls. During the second half-hour observation, Stacy spent $6 \mathrm{~min}$ in her bedroom playing on the computer, 16 min watching a television program with her father, and the last 8 min helping her mother bake cookies. Interactions between Stacy and her parents appeared very relaxed, and conversations centered on family activities and outings planned for that evening and the following day. Discussions regarding school, classmates, neighborhood friends, and peer group activities were nonexistent.

\section{Problem Analysis Stage}

The problem analysis stage of conjoint behavioral consultation involved a review of problem identification data across settings to confirm or invalidate the existence of a problem in need of remediation. During problem analysis, the goals of the school psychologist-consultant were to (a) assist the parent and teacher consultees in identifying factors that influenced Stacy's social difficulties; and (b) develop plans to attempt to solve the problem. These were accomplished through the inspection of baseline data and the Problem Analysis Interview (PAI).

Problem Analysis Interview. A conjoint Problem Analysis Interview was held between the psychologist and Stacy's parents and teacher. A review of baseline 
assessment data at that time suggested several conditions that may have influenced Stacy's social behaviors. First, it appeared that the limited opportunities to interact with peers at home, positive attention provided by Stacy's parents, and infrequent social participation of the entire family may have served as setting events to her overall lack of social interaction. Peers began neglecting Stacy when seeking interaction, so the antecedent conditions of peer proximity and availability for interaction were limited. Likewise, perhaps because of minimal peer involvement, Stacy's response repertoire appeared limited. Thus, it was likely that she failed to develop or refine the skills necessary to initiate, respond to, and continue social interactions successfully. The interactions that occurred were limited in duration and social meaning. As a result, her interactions were nonreinforcing to herself and to her peers.

The consultant interviewed Stacy's parents and teacher to obtain pretreatment information on the acceptability of various social skills treatment procedures. Specifically, four treatment procedures were described to her parents and teacher and questions were asked from the Behavior Intervention Rating Scale ${ }^{3}$ (Von Brock \& Elliott, 1987) to objectively identify their treatment preferences. Both parents and the teacher indicated that a social skills coaching procedure was most acceptable. Positive reinforcement procedures also were viewed favorably. Response cost and overcorrection procedures were perceived as aversive and were not desired by either Stacy's teacher or parents.

Following the interview about treatment acceptability, several modifications of the treatments were discussed with Stacy's parents and teacher to develop one that would enhance her social skills and decrease her withdrawn behavior. In keeping with the goals of conjoint behavioral consultation, consistent programming was desired across home and school.

\section{Treatment Implementation Stage}

A training method was needed to teach Stacy the skills necessary to respond to social initiations. Thus, a coaching procedure (Ladd, 1981; Oden \& Asher, 1977; Oden, 1986), which seemed appropriate and was evaluated most accept able by both parents and her teacher, was selected. Table 5 summarizes the major components of this coaching procedure.

The coaching procedure, based on Oden and Asher's (1977) research and refined through consultation, was instituted by Stacy's parents at home and by her teacher at school. Stacy's teacher met with Stacy every day for a week in "coaching sessions" to teach the concept of responding to social initiations made by peers. A coaching script was provided to Stacy's teacher, which included examples, nonexamples, questions, and behavioral role-play situations related to ap-

\footnotetext{
${ }^{3}$ The Behavior Intervention Rating Scale, or BIRS (Von Brock \& Elliott, 1987), is a 24-item scale on which treatments are evaluated for acceptability and perceived effectiveness; items are rated as 1 (strongly disagree) to 6 (strongly agree). The higher the total rating on the scale, the more positive the consumer finds the treatment.
} 
Table 5

Guidelines for a Coaching Intervention

Definition: "The provision of a conceptual framework that provides a model for behavior and a social context in which behavior may be modeled, shaped, and responded to with feedback" (Oden, 1986, p. 259).

General coaching procedures

1. Provide instruction of social skills concepts or rules for behavior.

2. Provide opportunity for practicing or rehearsing related behaviors.

3. Provide performance feedback on the new learning.

Coaching instructional process

1. Propose skill or concept.

2. Probe understanding.

3. Provide feedback/give direction.

4. Probe understanding/give specific examples.

a) Provide feedback/direction.

b) Probe understanding of consequences.

c) Probe understanding of opposites.

5. Probe understanding of further examples.

a) Provide feedback/direction.

b) Probe understanding of consequences.

c) Probe understanding of opposites.

6. Prompt trying out ideas.

7. Inform child of postperformance feedback.

8. Provide postperformance feedback/direction.

propriate responding behaviors. Performance feedback (i.e., positive reinforcement, prompting) was provided throughout each session.

Stacy's parents were instructed to review the concepts taught at school during social skills training at home. This included questioning Stacy's understanding of the concepts (i.e., starting, answering, and continuing social interactions), asking her for examples and nonexamples, and providing feedback. To encourage generalization across settings, the sessions included discussions and role-plays of ways that the skills could be practiced with friends in responding to peers outside of school.

To enhance treatment integrity (Gresham, 1989), Stacy's parents and teacher completed a treatment checklist (Table 6) daily, which detailed the objectives and procedures to be carried out in each session. The parents and teacher were successful in following the coaching procedures systematically, and thus it was concluded that the treatment was being implemented as prescribed.

Stacy's parents and teacher were asked to continue to collect data on her social behaviors. Specifically, they continued to record instances in which she initiated interactions with peers, instances in which she responded to initiations made by others, and the approximate length of time an interaction lasted.

During 2 weeks of the coaching procedure, Stacy's parents and teacher con- 
tinued to collect data on the frequency of initiating and responding behaviors. Likewise, the school psychologist-consultant conducted four direct observations of Stacy's social behavior at school, and three observations at home. Although Stacy appeared to respond favorably in the treatment sessions (as indicated in behavioral role-play situations), only slight increases in responding behaviors were apparent in noncoaching situations. Daily observational data collected at school indicated that Stacy responded positively to an average of $52 \%$ of initiations made by peers but still failed to initiate any interactions. Few opportunities for peer interactions occurred at home; thus the rate of responding remained low. A stronger program was desired to maximize treatment effectiveness across settings. This modification to strengthen the coaching treatment could have been predicted from previous research (see Schneider and Byrne meta-analysis); however, it was the clinical judgment of the consultant that to start with a more complex treatment would have undermined treatment integrity and the motivation of the consultees.

After consultation with all parties involved, modifications of the coaching intervention were planned. These involved the addition of treatment components to be implemented both at school and at home. The additional components were presented in a "package" format, including a Home-School Communication System, Paired Learning Activities, ${ }^{4}$ and Goal-Setting Procedures. Tables 7 and 8 highlight the major components of the latter two treatment components.

Table 6

Treatment Integrity Checklist for Coaching Procedures

The purpose of this checklist is to help you determine how well you were able to follow the coaching procedures with the child. This should assist you in your planning for subsequent sessions and activities.

At the end of each coaching session, complete the following checklist. Specifically, indicate on the line to the left of the item whether or not you were able to cover the content in adequate detail. If there are certain things that you are unsure of, please contact the consultant before continuing. The consultant will be available to provide feedback and suggestions.

1. Introduced skill components of answering (i.e., turning toward the other person,

looking at the other person, and answering the other person).

2. Probed understanding of the components of answering.

3. Provided specific feedback.

4. Demonstrated two examples of answering.

5. Demonstrated two examples of not answering.

6. Practiced skill of answering with the child.

7. Discussed examples for performing skill in other situations.

${ }^{4}$ Paired Learning Activities were developed to manipulate antecedent conditions to set the occasion for positive social interactions. They were based largely on the principles of cooperative learning (Madden \& Slavin, 1983) and Joint Task Activity procedures (Hops et al., 1978). Additional procedures for controlling antecedent conditions of prosocial behavior involve peer-mediated interventions and the use of peer confederates (Strain, Shores, \& Timm, 1977). 
The Home-School Communication System was established to enhance daily communication between Stacy's parents and teacher. Specifically, Stacy's responses to the intervention at home and school were shared. Carryover and generalization of appropriate behaviors were encouraged through prompting, dialogue, and positive reinforcement at home and school.

At school, Paired Learning Activities were structured to provide Stacy with daily opportunities to interact with one other peer during class. Three levels of activities were utilized, each requiring progressively greater amounts of self- initiated verbal interaction. Examples of Paired Learning Activities were oral reading with a peer, math flash cards, and peer interviews. Activities typically lasted 10 min, during which time Stacy's teacher observed the children and provided praise for appropriate turn-taking and verbal interaction.

A second addition to the original coaching intervention involved a daily goalsetting procedure. Specifically, Stacy, her teacher, and a peer "special helper" established daily goals and recorded them on a goal sheet. In the early phases of treatment, goals involved responding positively when approached by a peer. Examples of goals were "Responding to a question asked by a peer" and "Responding positively when asked to play a game." Stacy was responsible for self-monitoring goal attainment each day. She was given one point for attainment of each daily goal, and indications of all interactive behaviors were reinforced with verbal praise.

Similar treatment components were instituted by Stacy's parents at home. Specifically, a peer was invited over to Stacy's home twice per week to conduct paired learning activities. During these activities, Stacy's parent(s) praised her for taking turns and talking at the level specified by the activity. Treatment integrity was assessed through the completion by Stacy's parents of a Paired Learning Activity self-monitoring checklist. This also allowed the consultant to provide feedback to parents.

A home goal-setting procedure was invoked to facilitate generalization of skills from school to home. Upon returning from school, Stacy showed her par-

Table 7

Guidelines for Paired Learning Activities

Definition: A procedure that sets the occasion for positive social interactions between students by requiring them to work together on academic tasks.

General procedures

1. Select activities that require various levels of turn-taking and verbalization.

2. Pair child with nonwithdrawn peer.

3. Provide verbal praise to child and peer for taking turns and talking at (or above) the level of verbalization required for the activity.

Examples of paired learning activities

1. Math flash cards

2. Oral quizzes

3. Joint story writing

4. Peer interviews 
Table 8

Guidelines for Goal-Setting/Self-Monitoring Procedures

Definition: Enhancing one's social interactions by determining personal needs, developing objectives, and self-recording actions taken to meet the objectives.

General procedures

1. Meet with the child daily to help him/her develop personal goal.

2. Discuss specific actions required to meet the goal (i.e., provide examples of goal attainment, child behaviors and verbalizations, setting, participants).

3. Allow the child to select a reward from a reinforcement menu, to be earned contingent upon goal attainment.

4. Review the child's goal sheet immediately following goal attainment.

5. Provide verbal praise for all instances of interaction, and provide the chosen reward upon goal attainment.

Considerations in setting goals

1. Choose a goal that the child has control over.

2. Choose a goal that tells the student what to do, rather than what not to do.

3. Choose goals that the student will probably be successful in meeting.

4. Hook the student into the goal-setting process by keeping early goals easy enough to insure success.

5. Make goals specific enough for the child to follow them without confusion or indecision.

6. Insure better participation in the goal-setting process by having the student set goals with you.

7. Keep careful records of the goals that are set and the results of each goal on the goal chart.

Examples of goals

Ask a classmate what he/she did over the weekend.

Ask a friend to play a board game during recess.

Ask a friend to play hopscotch during recess.

Ask a group of friends to play a game at recess.

Ask a friend if he/she would like to help with a puzzle.

Ask a friend at least three questions about what they did over the weekend; a TV show they saw last night; their favorite sports event; a book they read; etc.

Ask a friend if he/she likes cards, what his/her favorite card game is, and then ask him/her to play.

Keep on playing until the game is over.

ents the goal sheet and discussed her daily goals. At the same time, Stacy and her parents set a goal for responding to social interactions at home. During the goalsetting procedures, Stacy and her parents discussed specific plans to meet her goals and practiced the steps to complete the goal as necessary.

A goal sheet similar to that used at school was used to record Stacy's performance at home. Immediately following attainment of a goal at home, Stacy reported to her parents the specific activities engaged in with her peers. Likewise, the goal sheet was used for Stacy to self-record attainment of her goal. Stacy earned one point for attainment of daily goals, and indications of all interactive behaviors were praised by her parents. Secondary reinforcers were provided at home, which were based on a total accumulation of four points, across both home and school settings. These were determined with the use of a reinforcement menu, from which Stacy chose the specific reward she worked towards. 
As with the other treatment components, the goal-setting situations were selfmonitored to assess treatment integrity. The evidence indicated that the treatments were being implemented with high integrity.

Following 1 week of intervention with the additional treatment components, significant increases were apparent in Stacy's responding behaviors. She was now responding to nearly $70 \%$ of peer initiations at school. Thus, identical procedures were instituted with a focus on initiating social interactions with peers. Specifically, a treatment package including Coaching, Paired Learning Activities, GoalSetting, and a Home-School Communication System was used to teach, provide opportunities for, and encourage Stacy's social initiation behaviors.

\section{Treatment Evaluation Stage}

The formal evaluation phase of this consultative intervention was undertaken following 2 weeks of baseline and 6 weeks of treatment. The evaluation process involved the steps of evaluating goal attainment and plan effectiveness, and postimplementation planning. Treatment evaluation was initiated through a treatment evaluation interview. Inspection of posttreatment data, and comparison with baseline and peer comparison data, facilitated the treatment evaluation process.

$\mathrm{An} \mathrm{AIB}+\mathrm{C}$ multiple-baseline design across behaviors was used to compare effectiveness of the treatment phases. Figure 1 depicts Stacy's initiating and responding behaviors at home and school, across all phases of the consultative intervention. Data were collected by Stacy's parents and teacher, with observational checks conducted by the school psychologist-consultant. A significant increase in Stacy's social interactive behaviors was noted with the introduction of the training package. By the end of the 6 weeks of treatment, Stacy consistently initiated five or six interactions at school per day, and responded to peer initiations $90 \%$ of the time. At home, she initiated an average of three interactions per day. Thus, she exceeded the initial daily goals of three peer initiations at school and one at home. Likewise, she exceeded the initial goal of responding positively to $85 \%$ of peer initiations.

The modified treatment program appeared effective in attaining the goal of increasing Stacy's social initiation and responding behaviors across settings. Likewise, the treatment appeared socially valid, in that Stacy's responding behaviors occurred at a level approximately equal to a nonwithdrawn peer's, while her initiating behaviors were only slightly less frequent than the peer comparison. Posttreatment ratings on the SSRS were completed by Stacy's parents and teacher, both reporting perceptions of an increased frequency of social initiating and responding behaviors. Thus, the consultation focus turned to providing recommendations for maintenance of the behavior change. Specifically, plans were established for fading the individual reinforcement, the paired learning activities, and finally the formal goal-setting/self-monitoring procedures at home and at school.

To assess the degree of behavior maintenance directly, a 6-week follow-up as- 
sessment was conducted. This involved direct observations of Stacy's interactive behaviors, a review of the treatment evaluation interview, and a follow-up sociometric rating. Stacy's increased level of prosocial behaviors appeared to be maintained over time. At follow-up, Stacy was observed initiating four peer interactions at school and three at home. Likewise, she responded positively to $85 \%$ of initiations made by peers. Sociometric measures identical to those utilized for screening purposes yielded an increased number of positive nominations, suggesting greater popularity with peers. Finally, Stacy's parents and teacher reported satisfaction with the behavior program and with the consultation services as assessed on the Behavior Intervention Rating Scale (Von Brock \& Elliott, 1987) and the Consultant Satisfaction Questionnaire (Zins, 1984).

\section{CONCLUSIONS}

When social skills are deficient, children often miss rewarding interpersonal opportunities and are more likely to experience negative consequences such as rejection. Thus, social skills interventions at school have been acknowledged as an important component in the treatment repertoire of school psychologists. The major goals of this article were to examine various empirically proven assessment and intervention methods that can be used to remediate social skills problems and to illustrate the utilization of these methods in a case study of a withdrawn elementary school child. To accomplish this goal, we briefly reviewed assumptions about social skills, outlined a four-category scheme for classifying and planning treatments for social skills deficits, and discussed the array of methods available to assess social behaviors of children.

It was concluded that a multimethod approach to assessment by which various raters (e.g., teachers, parents, self) use different methods (e.g., direct observation, rating scales, interviews) is desirable for selecting children with skills difficulties, identifying specific skill deficits, and evaluating treatment outcomes. The treatment options available for children with social skills deficits are numerous; however, the majority of effective interventions combine the manipulation of antecedents or consequences with modeling and coaching procedures. Regardless of the specific intervention used, it was demonstrated that the social validity of the intervention goals, procedures, and effects was fundamental to the maintenance and generalization of appropriate social behaviors. A two-phase treatment for a hypothetical withdrawn child was presented to illustrate the integration of this knowledge of social skills with judicious treatment planning and management.

Clearly, the marriage between science and practice is essential to the delivery of effective social skills interventions. It is recognized, however, that practical constraints often limit the amount of experimental rigor possible in applied research. As scientist-practitioners, school psychologists constantly must strive towards finding a balance between the demands of working within a complex and changing environment and of ensuring that their practice is empirically driven 
and ethically safeguarded. This is by no means an easy venture.

In attempts to apply optimal assessment and intervention procedures in practice, certain compromises will be necessary. For example, in the present case study our means of assessing treatment acceptability and integrity were relatively informal by comparison to methods typically used in the behavioral research literature. Such compromises do not necessarily diminish the utility of carefully planned, well-documented case studies. In an effort to approach experimental integrity and promote "best" practices in social skills assessment and intervention, consideration of the strategies aforementioned by scientists and practitioners alike is strongly encouraged.

\section{REFERENCES}

Achenbach, T. M., \& Edelbrock, C. (1983). Manual for the Child Behavior Checklist and Revised Child Behavior Profile. Burlington, VT: University of Vermont Department of Psychiatry.

Achenbach, T. M., \& Edelbrock, C. (1986). Manual for the Teacher's Report Form and Teacher Version of the Child Behavior Profile. Burlington, VT: University of Vermont Department of Psychiatry.

Achenbach, T. M., McConaughy, S. H., \& Howell, C. T. (1987). Child/adolescent behavioral and emotional problems: Implications of cross-informant correlations for situational specificity. Psychological Bulletin, 101, 213-232.

Bandura, A. (1977). Social learning theory. Englewood Cliffs, NJ: Prentice-Hall.

Barclay, J. R. (1978). Appraising individual differences in the elementary classroom: A manual for the Barclay Classroom Assessment System. Lexington, KY: Educational Skills Development, Inc.

Bergan, J. R. (1977). Behavioral consultation. Columbus, OH: Merrill.

Berler, E. S., Gross, A. M., \& Drabman, R. S. (1982). Social skills training with children: Proceed with caution. Journal of Applied Behavior Analysis, 15, 41-43.

Bullock, M. J., Ironsmith, M., \& Poteat, G. M. (1988). Sociometric techniques with young children: A review of psychometrics and classification schemes. School Psychology Review, 17, 289-303.

Coie, J. D., \& Dodge, K. A. (1983). Continuity of children's social status: A five-year longitudinal study. Merrill-Palmer Quarterly, 29, 261-282.

Coie, J. D., Dodge, K. A., \& Coppotelli, H. (1982). Dimensions and types of social status: A cross-age perspective. Developmental Psychology, 18, 557-570.

Coie, J. D., \& Krehbiel, G. (1984). Effects of academic tutoring on the social status of low-achieving, socially rejected children. Child Development, 55, 1465-1478.

Cowen, E. L., Pederson, A., Babigian, H., Izzo, L. D., \& Trost, M. D. (1972). Long term follow-up of early detected vulnerable children. Journal of Consulting and Clinical Psychology, 41, 438-446.

Dodge, K. A., Murphy, R., \& Buchsbaum, D. (1984). The assessment of intention-cue detection skills in children: Implications for developmental psychopathology. Child Development, 55, 163-173. 
Elliott, S. N. (1988, April). Assessment of social skills deficits: Current methods and measurement issues. Paper presented at the Annual Convention of the American Educational Research Association, New Orleans.

Elliott, S. N., Gresham, F. M., \& Heffer, R. W. (1987). Social skills interventions. In C. A. Maher \& J. Zins (Eds.), Psychoeducational interventions in schools (pp. 141-159). New York: Pergamon.

Gresham, F. M. (1981). Assessment of children's social skills. Journal of School Psychology, 19, 120-133.

Gresham, F. M. (1989). Assessment of treatment integrity. School Psychology Review, 18, $37-50$.

Gresham, F. M., \& Cavell, T. A. (1986). Assessing adolescent social skills. In R. G. Harrington (Ed.), Testing adolescents: A reference guide for comprehensive psychological assessments (pp. 93-122). Kansas City, MO: Test Corporation of America.

Gresham, F. M., \& Elliott, S. N. (1984). Assessment and classification of children's social skills: A review of methods and issues. School Psychology Review, 13, 292-301.

Gresham, F. M., \& Elliott, S. N. (1987). The relationship between adaptive behavior and social skills. Journal of Special Education, 21, 167-182.

Gresham, F. M., \& Elliott, S. N. (in press). Social Skills Rating System. Circle Pines, MN: American Guidance Service.

Gresham, F. M., \& Reschly, D. J. (1988). Issues in the conceptualization, classification, and assessment of social skills in the mildly handicapped. In T. R. Kratochwill (Ed.), Advances in school psychology (Vol. 6, pp. 203-248). Hillsdale, NJ: Erlbaum.

Harter, S. (1985). Manual for the Self-Perception Profile for Children. Denver: University of Denver Press.

Hops, H., Guild J., Fleischman, D. H., Paine, S. C., Street, A., Walker, H. M., \& Greenwood, C . R. (1978). Procedures for establishing effective relationship skills (PEERS); Consultant manual. Eugene, OR: University of Oregon, Center at Oregon for Research in Behavioral Education of the Handicapped.

Kazdin, A. E. (1985). Selection of target behaviors: The relationship of the treatment focus to clinical dysfunction. Behavioral Assessment, 7, 33-47.

Kratochwill, T. R., \& Bergan, J. R. (in press). Behavioral consultation in applied settings: An individual guide. New York: Pergamon.

Ladd, G. W. (1981). Effectiveness of a social learning method for enhancing children's social interaction and peer acceptance. Child Development, 52, 171-178.

Madden, N. A., \& Slavin, R. E. (1983). Mainstreaming students with mild academic handicaps: Academic and social outcomes. Review of Educational Research, 53, 519-569.

Mastropieri, M. A,, \& Scruggs, T. E. (1985-1986). Early intervention for socially withdrawn children. Journal of Special Education, 19, 429-441.

McConnell, S. R., \& Odom, S. L. (1986). Sociometrics: Peer-referenced measures and the assessment of social competence. In P. S. Strain, M. J. Guralnick, \& H. M. Walker (Eds.), Children's social behavior: Development, assessment, and modification (pp. 215-285). Orlando, FL: Academic.

Michelson, L., Sugai, D. P., Wood, R. P., \& Kazdin, A. E. (1983). Social skills assessment and training with children: An empirically based approach. New York: Plenum.

Nelson, R., \& Hayes, S. (1979). Some current dimensions of behavioral assessment. Behavioral Assessment, 1, 1-16. 
Oden, S. (1986). A child's social isolation: Origins, prevention, intervention. In G. Cartledge \& J. F. Milburn (Eds.), Teaching social skills to children (pp. 246-269). New York: Pergamon.

Oden, S. L., \& Asher, S. R. (1977). Coaching children in social skills for friendship making. Child Development, 48, 496-506.

Parker, J. G., \& Asher, S. R. (1987). Peer relations and later personal adjustment: Are lowaccepted children at risk? Psychological Bulletin, 102, 357-389.

Peery, J. C. (1979). Popular, amiable, isolated, rejected: A reconceptualization of sociometric status in preschool children. Child Development, 50, 1231-1234.

Roff, M., Sells, S. B., \& Golden, M. M. (1972). Social adjustment and personality development in children. Minneapolis: University of Minnesota Press.

Schneider, B. H., \& Byrne, B. M. (1985). Children's social skills: A meta-analysis. In B. H. Schneider, K. H. Rubin, \& J. E. Ledingham (Eds.), Children's peer relations: Issues in assessment and intervention (pp. 175-192). New York: Springer-Verlag.

Schneider, B. H., \& Byrne, B. M. (1988, April). Meta-analysis of children's social skills interventions: A reanalysis. Paper presented at the Annual Convention of the American Educational Research Association, New Orleans.

Sheridan, S. M. (1988). Conjoint behavioral consultation: A link between home and school settings. Unpublished doctoral dissertation proposal, University of Wisconsin-Madison.

Stokes, T., \& Baer, D. (1977). An implicit technology of generalization. Journal of Applied Behavior Analysis, 19, 349-367.

Strain, P. S., Shores, R. E., \& Timm, M. A. (1977). Effects of peer initiations on the social behavior of withdrawn preschool children. Journal of Applied Behavior Analysis, 10, 289-298.

Von Brock, M. B., \& Elliott, S. N. (1987). The influence of treatment effectiveness information on the acceptability of classroom interventions. Journal of School Psychology, 25, 131-144.

Vosk, B., Forehand, R., Parker, J. B., \& Rickard, K. (1982). A multimethod comparison of popular and unpopular children. Developmental Psychology, 18, 571-575.

Weissberg, R. P. (1985). Designing effective social problem-solving programs for the classroom. In B. H. Schneider, K. H. Rubin, \& J. E. Ledingham (Eds.), Children's peer relations: Issues in assessment and intervention (pp: 225-242). New York: Springer-Verlag.

Zins, J. E. (1984). A scientific problem-solving approach to developing accountability procedures for school psychologists. Professional Psychology: Research and Practice, $15,56-66$. 